\title{
Ambulatory blood pressure monitoring greatly improves diagnostic accuracy in excess and normal weight children
}

\author{
Cristina Ramona Radulescu', Ioana Adriana Ghiorghiu1,2, Ana-Maria Berchimis ${ }^{2,3}$, \\ Mihaela Dascalasu ${ }^{1,2,3}$, Gabriela Vlad², Doina Anca Plesca ${ }^{1,2}$ \\ 1"Carol Davila" University of Medicine and Pharmacy, Bucharest, Romania \\ 2"Dr. Victor Gomoiu" Clinical Children's Hospital, Bucharest, Romania \\ ${ }^{3}$ Ponderas Academic Hospital, Bucharest, Romania
}

\begin{abstract}
Introduction. Given the significant levels of pediatric excess weight worldwide, we sought to identify the prevalence of abnormally high BP levels (based on auscultatory measurements and ambulatory blood pressure monitoring ABPM) in a cohort of excess weight children compared to normal weight controls and to analyze the effect of weight loss on BP measurements in the excess weight group.

Method. 46 excess weight children and 28 normal weight controls underwent clinical examination, routine blood tests and lipid profile, 12-lead ECG, ABPM and echocardiography. For the excess weight group lifestyle advice was provided and children were subsequently followed up for 12 months.

Results. The auscultatory method yielded high rates of arterial hypertension (HTN) $(50-58 \%$ in the study group and $22-33 \%$ in the control group). There was a statistically significant difference in HTN prevalence between the two groups regardless of the standard used to define it. BMl-for-age correlated positively with HTN. The corresponding BP category was generally higher when applying the Unites States guideline.

There was a prevalence of HTN of $14.3 \%$ in the study group and $4 \%$ in the control group according to ABPM results $(t(51)=1.274, p=0.208$, C.I. [-0.06, 0.26$]) .48 .3 \%$ of excess weight children and $56 \%$ of controls were non-dippers. There was no significant association between dipping status and ABPM-confirmed hypertension. $64 \%$ of excess weight participants exhibited dipping status variability.

There was a small, but statistically significant improvement of BMI-for-age within the excess weight group over the follow-up period. There was however no significant drop in HTN levels. HTN prevalence remained much lower when diagnosed by means of ABPM (16.7\%) than by manual measurements $(42.9 \%)$.

Discussion. There was a surprisingly high prevalence of arterial hypertension based on manual measurements, mainly driven by high systolic BP values. The numbers decreased significantly after ABPM-based reclassification. Another unexpected find was the high proportion of non-dippers in both groups, which could be partially explained by fragmented, poor quality sleep during monitoring.

Conclusions. We found an unexpectedly high prevalence of increased BP levels for age when using manual, in-office measurements only. Ambulatory BP monitoring with pediatric approved devices has proved extremely useful in refining the diagnosis and should thus be employed for confirmation if available.

There was an increased prevalence of hypertension in the excess weight group and BMI-for-age correlated positively with BP values. We were unable to demonstrate a reduction in BP levels with improved nutritional status, however we believe this may be achieved with an adequately sized cohort and more stringent lifestyle intervention.
\end{abstract}

Keywords: excess weight, hypertension, auscultatory, oscillometric, ABPM, dipper

\section{INTRODUCTION}

There is a known connection between excess weight and blood pressure (BP) levels, this relationship being clearly documented in adults (1-3). It is also postulated that weight loss promotes lower BP levels and improved control with treatment (4). The phenomenon has been studied perhaps less intensely in children, but is nevertheless well documented in pediatric cohorts5. This is consistent with local data, relevant Romanian literature quoting a prevalence of 12 to $24 \%$ in overweight and obese children (6-9).

There are several ways to measure blood pressure in children. Historically, the most widely used has been the auscultatory (manual) method (on which most normative data used to derive normal values are 
based), but over the years the oscillometric (automated) method has gained momentum. In addition, ambulatory blood pressure monitoring (ABPM) and home BP monitoring are increasingly being employed. Normal pediatric values take into account sex, age and height (10-12).

Given the significant levels of pediatric excess weight worldwide, we sought to identify the prevalence of abnormally high BP levels (based on auscultatory measurements and ABPM) in a cohort of excess weight children compared to normal weight controls and to analyze the effect of weight loss on BP measurements in the excess weight group.

\section{METHOD}

46 excess weight (overweight or obese), otherwise healthy children and 28 normal weight, healthy controls were enrolled in the study. Weight was assessed according to the Centers for Disease Control and Prevention (CDC) criteria (13) using an online calculator (14). Excess weight children received a written plan of necessary lifestyle interventions, the purpose being to lower the corresponding body mass index (BMI)for-age percentile, ideally to less than 85 . They were subsequently scheduled for two additional clinical follow-up visits at 6 months intervals (referred to as V6 and V12). The normal weight controls were only examined once; both the controls' visit and the initial visit for the excess weight group were labeled V0. Each visit comprised clinical examination, routine blood tests, total serum cholesterol and triglyceride levels, 12-lead ECG, 24 hour ABPM and echocardiography.

Auscultatory BP was determined in both arms using an appropriately sized cuff, the higher reading of the two being used for staging. If the initial reading was high, the measurement was repeated at least once during the same visit; in this case we recorded the lowest reading obtained. Staging was performed using both the European (EU) and United States (US) published guidelines $(10,11)$.

ABPM was performed using an oscilllometric device (either BTL-08 ABPM SW or Mortara Ambulo 2400) and an appropriately sized cuff. The monitor was applied to the non-dominant arm and was programmed to record BP every 30 minutes during waking hours and every 60 minutes during sleep. Participants and parents were advised to maintain normal levels of physical activity while wearing the device. Recordings were considered valid if at least $70 \%$ of readings were available for a full study. We recorded mean 24-hour, awake and asleep systolic BP (SBP) and diastolic BP (DBP), minimum and maximum BP values, mean 24-hour heart rate, BP load and dipping (percent day/night difference). Participants were dee- med dippers if the difference exceeded $10 \%$, non-dippers if there was a 0 to $10 \%$ difference or reverse dippers if it was less than $0 \%$. ABPM results were interpreted using the 2014 US recommendations (12).

\section{RESULTS}

Baseline participant characteristics may be found in Table 1. 12-lead ECGs and echocardiographic examinations were normal at baseline and remained normal throughout the study for the excess weight group.

TABLE 1. Participant characteristics at VO; SD - standard deviation; NS - not significant; *according to (15)

\begin{tabular}{|c|c|c|c|}
\hline Category & Excess weight & Control & P value \\
\hline \multicolumn{4}{|l|}{ General } \\
\hline \multicolumn{4}{|l|}{ Age (years) } \\
\hline Mean \pm SD & $10.31 \pm 3.1$ & $13.06 \pm 3.58$ & \multirow{2}{*}{$<0.01$} \\
\hline Median (range) & $9.95(2.45-16.42)$ & $13.83(4.58-17.75)$ & \\
\hline Male (\%) & 43.3 & 39.3 & NS \\
\hline Urban (\%) & 76.1 & 71.4 & NS \\
\hline $\begin{array}{l}\text { BMI-for-age (mean } \\
\text { percentile } \pm S D \text { ) }\end{array}$ & $96.76 \pm 2.4$ & $51.96 \pm 23.5$ & $<0.01$ \\
\hline \multicolumn{4}{|c|}{ History } \\
\hline $\begin{array}{l}\text { Birth weight, mean } \\
\text { (g) }\end{array}$ & 3183.8 & 3207.3 & NS \\
\hline $\begin{array}{l}\text { Birth length, mean } \\
(\mathrm{cm})\end{array}$ & 51.3 & 51.1 & NS \\
\hline $\begin{array}{l}\text { History of excess } \\
\text { weight (\%) }\end{array}$ & 23.9 & 3.6 & $<0.05$ \\
\hline \multicolumn{4}{|c|}{ Lipid profile } \\
\hline $\begin{array}{l}\text { Modified* total } \\
\text { cholesterol (\%) }\end{array}$ & 64.9 & 26.9 & $<0.01$ \\
\hline $\begin{array}{l}\text { Modified* } \\
\text { triglycerides (\%) }\end{array}$ & 50 & 20 & $<0.05$ \\
\hline
\end{tabular}

Auscultatory BP readings were available for all participants at V0. There was a statistically significant difference in arterial hypertension (HTN) prevalence between the two groups regardless of the standard used to define it. When including elevated BP levels in the analysis, percentages become similar according to the US criteria (Table 2).

TABLE 2. Prevalence of increased BP values and HTN according to European (EU) and United States (US) guidelines; NS - not significant

\begin{tabular}{|l|c|c|c|c|c|c|}
\hline & \multicolumn{3}{|c|}{ EU } & \multicolumn{2}{c|}{ US } \\
\hline & $\begin{array}{c}\text { Excess } \\
\text { weight } \\
\text { (V0) }\end{array}$ & Control & P value & $\begin{array}{c}\text { Excess } \\
\text { weight } \\
\text { (V0) }\end{array}$ & Control & P value \\
\hline $\begin{array}{l}\text { Increased } \\
\text { BP (high- } \\
\text { normal/ } \\
\text { elevated or } \\
\text { HTN) }\end{array}$ & $67.4 \%$ & $39.3 \%$ & $<0.05$ & $67.4 \%$ & $67.9 \%$ & NS \\
\hline $\begin{array}{l}\text { HTN (either } \\
\text { stage) }\end{array}$ & $50 \%$ & $22.2 \%$ & $<0.05$ & $58.7 \%$ & $32.1 \%$ & $<0.05$ \\
\hline
\end{tabular}




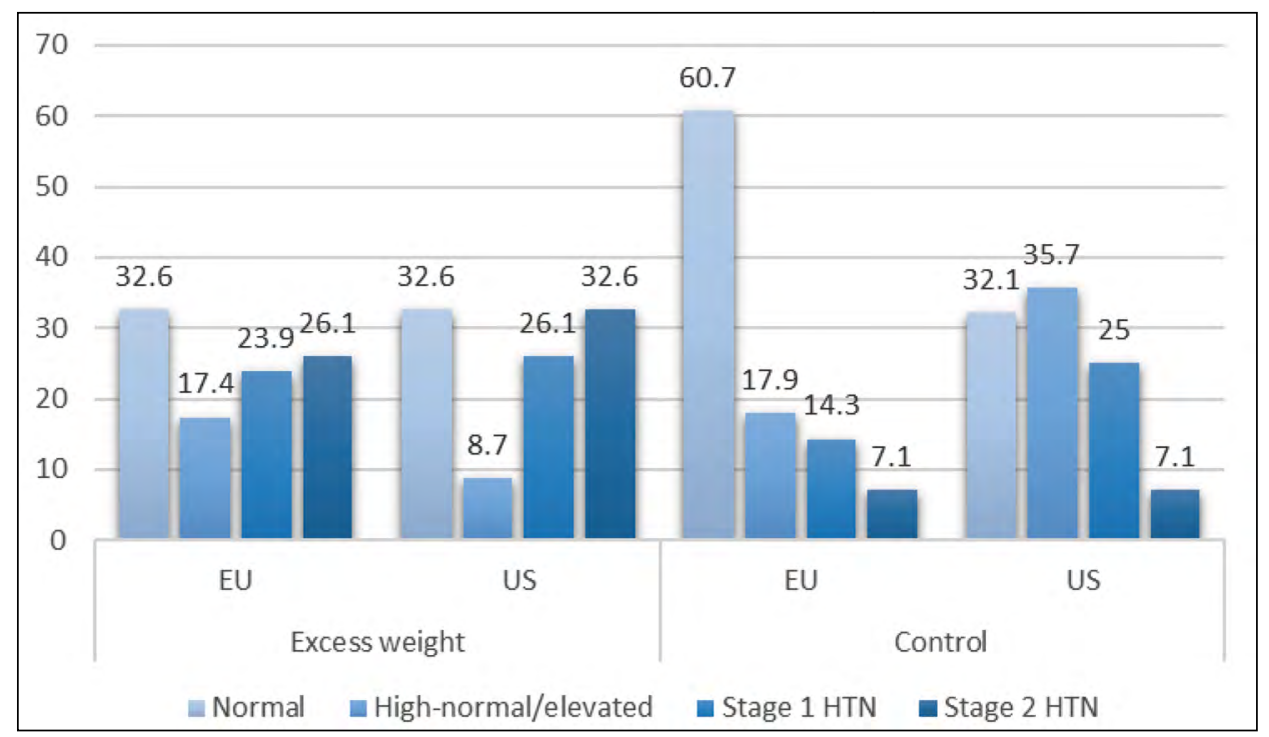

FIGURE 1. BP staging (\%) according to the European (EU) and United States (US)

guidelines. HTN - hypertension

A higher number of excess weight children were categorized as stage 2 HTN using the US standard (32.6\% as opposed to $26.1 \%)$. Conversely, more children had either high-normal values or stage 1 HTN when employing the EU standard. Children with normal BP values were deemed as such regardless of standard. In the control group, more children had either elevated BP or stage 1 HTN by US standards, whereas more participants had normal BP values when using EU standards (Figure 1).

BMI-for-age correlated positively with HTN (either stage) diagnosed by US standards $(\mathrm{r}(72)=0.29, \mathrm{p}$ $=0.011)$ or EU standards $(\mathrm{r}(72)=0.28, \mathrm{p}=0.016), \mathrm{r}^{2}$ $=0.08$.

By analyzing systolic and diastolic components using the US standard - where it was possible to obtain the exact percentile using online calculators $(16,17)$ -, we noted that, for participants with increased BP levels, the systolic component was equivalent to a significantly higher percentile $(\mathrm{M}=92.9, \mathrm{SD}=9.5)$ than the diastolic component $(\mathrm{M}=86.46, \quad \mathrm{SD}=15)$, $\mathrm{t}(49)=2.85, \mathrm{P}=0.006,95 \%$ C.I. $[1.9,11]$. The same is observed when only analyzing hypertensive children: systolic component $\mathrm{M}=95.86, \mathrm{SD}=6.1$, diastolic component $\mathrm{M}=91.25, \mathrm{SD}=10.7, \mathrm{t}(35)=2.2, \mathrm{P}=0.035$, 95\% C.I. $[0.34,8.88]$.

It was not possible to perform ABPM in all patients, either because of parent/carer (or child) refusal or because the family did not keep their appointment. In the end, $90.5 \%$ (excess and normal weight children, V0), 96.3\% (V6) and 90.9\% (V12) children were monitored. Of these, $80.6 \%$ (V0), $53.8 \%$ (V6) and $65 \%(\mathrm{~V} 12)$ of results were considered valid and interpreted (mean percentage of valid recordings
$83.7 \%$ ). The mean duration of wear was 21.74 hours.

There was a prevalence of HTN of $14.3 \%$ in the experimental group and $4 \%$ in the control group according to ABPM results at V0 (variation did not reach statistical significance $(\mathrm{t}(51)=1.274, \mathrm{p}=0.208$, C.I. $[-0.06,0.26])$. The difference in HTN prevalence as diagnosed by manual (auscultatory) measurement as opposed to ABPM is statistically significant (Table 3). Normal BP levels were later confirmed by random, repeated home BP monitoring performed by parents/ carers in the excess weight group.

TABLE 3. HTN prevalence in the two groups varies significantly with measurement method

\begin{tabular}{|l|c|c|c|c|}
\hline & \multicolumn{2}{|c|}{ EU } & \multicolumn{2}{c|}{ US } \\
\hline & $\begin{array}{c}\text { Excess weight } \\
\text { (V0) }\end{array}$ & Control & $\begin{array}{c}\text { Excess weight } \\
\text { (V0) }\end{array}$ & Control \\
\hline $\begin{array}{l}\text { HTN prevalence } \\
\text { (manual) }\end{array}$ & $53.1 \%$ & $21.7 \%$ & $56.3 \%$ & $33.3 \%$ \\
\hline $\begin{array}{l}\text { HTN prevalence } \\
\text { (ABPM) }\end{array}$ & $14.3 \%$ & $4 \%$ & $14.3 \%$ & $4 \%$ \\
\hline P value & $<0.01$ & $<0.05$ & $<0.01$ & 0.01 \\
\hline
\end{tabular}

There were $51.7 \%$ dippers, $48.3 \%$ non-dippers and no reverse dippers at $\mathrm{V} 0$ in the experimental group as opposed to $40 \%$ dippers, $56 \%$ non-dippers and one $(4 \%)$ reverse dipper in the control group, $\mathrm{t}(52)=$ $1.269, \mathrm{P}=$ NS, C.I. $=[-0.1,0.4]$. There was no significant association between dipping status and ABPMconfirmed hypertension. $64 \%$ of excess weight group participants (which had at least two valid ABPM results) exhibited variability of the dipping status.

At V12 less than $50 \%$ of excess weight children remained in the study. At this stage, two participants were being treated for hypertension. There was a 
small, but statistically significant improvement of BMI-for-age within the group between V0 and V12 $(\mathrm{t}(21)=2.22, \mathrm{P}=0.037,95 \%$ C.I. $[0.13,3.8])$. There was however no significant drop in HTN prevalence at V12. HTN prevalence (treated children excluded) remained much lower when diagnosed by means of ABPM $(16.7 \%)$ than by manual measurements $(42.9 \%)$

\section{DISCUSSION}

There were significant differences in withingroups BP staging according to the standard used (EU or US). There could be several possible explanations:

Both guidelines recommend transitioning to adult values after a certain age, which is lower (13 years) for the US guideline;

Mean age was higher in the control group, which may explain the higher proportion of children with increased BP values according to the US guideline;

Both guidelines align with current local adult recommendations $(18,19)$, abnormal BP levels being lower in the US guideline.

A comparison between the European (10) (EU) and United States (11) (US) pediatric guidelines is provided in Table 4.

While differences in staging according to the two guidelines were to be expected to some extent, the same cannot be said about the surprisingly high prevalence of arterial hypertension based on manual (auscultatory) measurements only: around $50 \%$ of excess weight children were deemed hypertensive and even in the control group there was a 22 to $33 \%$ prevalence of HTN. According to our data, this was mainly due to high systolic BP values. These rates exceed (by far) those reported in international literature and may very well represent a unique trait of our groups, which were rather small, or may be related to anxiety brought on by an in-hospital setting. The numbers decreased significantly after ABPM-based reclassification, reaching $14.3 \%$ in the experimental group and just $4 \%$ in the control group.

There are, however, some difficulties with ABPM in children, especially at very young ages. In our study, some parents, legal guardians or children refused the monitor. Not all results were valid, and even in valid results there was a rather low percentage of accurate readings (average of around 84\%). Last, but not least, pediatric ABPM devices are not readily available in all facilities and recordings are time-consuming and costly when compared to the inexpensive alternative of a manual measurement.

Regardless of BP measurement method (manual or by ABPM), the percentage of HTN was higher in the excess weight group and there was a positive correlation between BMI-for-age and BP values. However, the effect size was small in our study $\left(r^{2}=0.08\right)$.

Another surprising find was the high proportion on non-dippers in both groups. For adults with HTN, a non-dipper profile was linked to more severe hypertensive target organ damage and higher cardiovascular (CV) risk (20). For normotensive individuals things are less clear, although there is some evidence that even in this case CV risk levels may be higher (21). Data regarding the dipping profile is rather scarce for children and even more so for normotensive children. Dipping is defined in a similar manner to adults (12). There are studies that pointed to a link between obesity and non-dipping (22), which was not

TABLE 4. Definition of BP categories according to guidelines. EU, European. US, United States. SBP, systolic blood pressure. DBP, diastolic blood pressure. N/A, not available. *term used in the US guideline.

\begin{tabular}{|c|c|c|c|c|}
\hline & $\begin{array}{l}\text { EU, 0-15 years } \\
\text { SBP and/or DBP } \\
\text { (percentile) }\end{array}$ & $\begin{array}{c}\text { US, } 0-13 \text { years } \\
\text { SBP and/or DBP } \\
\text { (percentile) }\end{array}$ & $\begin{array}{c}\text { EU, } \geq 16 \text { years } \\
\text { SBP and/or DBP }(\mathrm{mmHg})\end{array}$ & $\begin{array}{c}\text { US, } \geq 13 \text { years } \\
\text { SBP and/or DBP }(\mathrm{mmHg})\end{array}$ \\
\hline Normal & $<90$ th & $<90$ th & $<130 / 85$ & $<120 /<80$ \\
\hline High-normal (elevated*) & $\geq 90$ th to $<95$ th & $\begin{array}{c}\geq 90 \text { th to }<95 \text { th or } 120 / 80 \\
\mathrm{mmHg} \text { to }<95 \text { th (whichever } \\
\text { is lower) }\end{array}$ & $130-139 / 85-89$ & $120 /<80$ to $129 /<80$ \\
\hline Hypertension & $\geq 95$ th & $\geq 95$ th & $\geq 140 / 90$ & $\geq 130 / 80$ \\
\hline Stage 1 hypertension & 95th - 99th and $5 \mathrm{mmHg}$ & \begin{tabular}{|c|}
$\geq 95$ th to $<95$ th $+12 \mathrm{mmHg}$ \\
or $130 / 80$ to $139 / 89 \mathrm{mmHg}$ \\
(whichever is lower)
\end{tabular} & 140-159/90-99 & $130 / 80$ to $139 / 89$ \\
\hline Stage 2 hypertension & $>99$ th plus $5 \mathrm{mmHg}$ & $\begin{array}{c}\geq 95 \mathrm{th}+12 \mathrm{mmHg} \text {, or } \\
\geq 140 / 90 \mathrm{mmHg} \text { (whichever } \\
\text { is lower) }\end{array}$ & $160-179 / 100-109$ & $\geq 140 / 90$ \\
\hline $\begin{array}{l}\text { Isolated systolic } \\
\text { hypertension }\end{array}$ & SBP $\geq 95$ th and $D B P<90$ th & $\mathrm{N} / \mathrm{A}$ & $\geq 140 /<90$ & $\mathrm{~N} / \mathrm{A}$ \\
\hline
\end{tabular}


observed in the present study. Published data regarding a possible association with HTN is conflicting $(23,24)$; no relationship was noted in our cohort.

In our study, two factors may at least partially explain the high percentage of non-dippers:

In order to increase compliance with the ABPM monitor, the devices were programmed to record $\mathrm{BP}$ at 1 hour intervals during sleep, which in turn lead to fewer nighttime readings;

Quite a large number of participants reported waking up with nighttime measurements, thus having poor-quality, fragmented sleep.

It is unclear based on our data if the dipping profile could be of major relevance in the pediatric setting.

The BMI-for-age percentile improvement we aimed for in the excess weight group was modest over the follow-up period of one year, the parameter actually increasing in some cases. Also to note, as a negative factor, the small percentage (under 50\%) of excess weight participants that actually completed the study. Perhaps for these reasons the small nutritional status improvement did not result in an improved BP profile in these children.

\section{REFERENCES}

1. McCarron DA, Reusser ME. Body weight and blood pressure regulation. Am J Clin Nutr. 1996;63:423S-425S

2. Mertens IL,Van Gaal LF. Overweight, obesity, and blood pressure: The effects of modest weight reduction. Obes Res. 2000;8:270-278.

3. Neter JE, Stam BE, Kok FJ, Grobbee DE, Geleijnse JM. Influence of Weight Reduction on Blood Pressure: A Meta-Analysis of Randomized Controlled Trials. Hypertension. 2003;42;878-884.

4. Sabaka $P$ et al. The effects of body weight loss and gain on arterial hypertension control: An observational prospective study. Eur J Med Res. 2017;22.

5. Parker ED et al. Change in weight status and development of hypertension. Pediatrics. 2016;137:e20151662.

6. Novac O. et al. Assessment of complications of excess weight in school-age children and adolescents. Rev Med Chir Soc Med Nat. lasi 2009;113:740-744.

7. Cinteză $E$, Balgradean M. Hypertension in romanian children and adolescents: a cross-sectional survey. Maedica (Buchar). 2013;8:5-10.

8. Chiriţă-Emandi A, Puiu M, Gafencu M, Pienar C. Arterial hypertension in school-aged children in western Romania. Cardiol Young. 2013;23:189-196.

9. Luca AC, lordache C. Obesity - a risk factor for cardiovascular diseases. Rev Med. Chir Soc Med Nat. lasi 2013;117:65-71.

10. Lurbe $E$ et al. 2016 European Society of Hypertension guidelines for the management of high blood pressure in children and adolescents. J Hypertens. 2016;34:1887-1920.

11. Flynn JT et al. Clinical practice guideline for screening and management of high blood pressure in children and adolescents. Pediatrics. 2017; 140:e20171904.

12. Flynn JT et al. Update: Ambulatory blood pressure monitoring in children and adolescents: A scientific statement from the American Heart Association. Hypertension. 2014;63;1116-1135.

13. Kuczmarski RJ, Ogden CL, Guo SS et al. 2000 CDC Growth Charts for the United States: methods and development. Vital Health Stat 11. 2002; (246): $1-190$.

14. Centers for Disease Control and Prevention. BMI Percentile Calculator for Child and Teen. Centers for Disease Control and Prevention (2019). Available at: https://www.cdc.gov/healthyweight/bmi/calculator.html (Accessed: 29th April 2020)

\section{CONCLUSIONS}

We found an unexpectedly high prevalence of increased BP levels for age when using manual, in-office measurements only. These were mainly driven up by the systolic component and were not confirmed by ambulatory blood pressure monitoring in most cases, which led us to believe that anxiety related to the interaction with a medical professional in an in-hospital setting was a major contributing factor. Ambulatory BP monitoring with pediatric approved devices has proved extremely useful in selecting the few with actual raised BP, guiding treatment strategy, and should thus be employed to confirm the diagnosis if available.

There was an increased prevalence of hypertension in the excess weight group and BMI-for-age correlated positively with $\mathrm{BP}$ values. We were unable to demonstrate a reduction in BP levels with improved nutritional status; however, since the study group was rather small and BMI-for-age percentile reduction modest, we believe this may be achieved with an adequately sized cohort and more stringent lifestyle intervention.

\section{Conflict of interest: none declared Financial support: none declared}

15. Grundy SM et al. 2018 AHA/ACC/AACVPR/AAPA/ABC/ACPM/ADA/ AGS/APhA/ASPC/NLA/PCNA Guideline on the Management of Blood Cholesterol: A Report of the American College of Cardiology/American Heart Association Task Force on Clinical Practice Guidelines. Circulation 2019;139:E1082-E1143.

16. Shypailo R. Age-based Pediatric Blood Pressure Reference Charts. Baylor College of Medicine, Children's Nutrition Research Center, Body Composition Laboratory Web Site (2018). Available at: https://www.bcm.edu/ bodycomplab/BPappZjs/BPvAgeAPPz.html (Accessed: 7th May 2020).

17. Flynn JT, Rosner B. AAP Pediatric Hypertension Guidelines - MDCalc. American Academy of Pediatrics via MDCalc (2017). Available at: https:// www.mdcalc.com/aap-pediatric-hypertension-guidelines (Accessed: 7th May 2020).

18. Whelton PK et al. 2017 ACC/AHA/AAPA/ABC/ACPM/AGS/APhA/ASH/ ASPC/NMA/PCNA guideline for the prevention, detection, evaluation, and management of high blood pressure in adults: Executive summary: $A$ report of the American college of cardiology/American Heart Association task. Hypertension. 2018;71;1269-1324.

19. Williams B et al. $2018 \mathrm{ESC} / \mathrm{ESH}$ Guidelines for the management of arterial hypertension: The Task Force for the management of arterial hypertension of the European Society of Cardiology (ESC) and the European Society of Hypertension (ESH). Eur Heart J. 2018;39:3021-3104.

20. Birkenhäger AM, Van der Meiracker AH. Causes and consequences of a non-dipping blood pressure profile. Netherlands Journal of Medicine 2007:65:127-131.

21. Hermida RC, Ayala DE, Mojón A, Fernández JR. Blunted sleep-time relative blood pressure decline increases cardiovascular risk independent of blood pressure level - The 'Normotensive Non-dipper' paradox. Chronobiol Int. 2013;30;87-98.

22. Macumber IR, Weiss NS, Halbach SM, Hanevold CD, Flynn JT. The Association of Pediatric Obesity With Nocturnal Non-Dipping on 24-Hour Ambulatory Blood Pressure Monitoring. Am J Hypertens. 2016;29;647-652.

23. Belaha CW, Wells TG, Plummer JK, Roberson PK, Berry PL. Blood pressure patterns in normotensive and hypertensive children and adolescents. J Investig Med. 1997;44:801-806.

24. Krzych LJ, Syzdlowski L. Determinants of inappropriate circadian blood pressure variability in children with essential hypertension. Can J Cardiol. 2009;25:e13. 